\title{
Meta-performance evaluation of sustainability indicators
}

\author{
Tomás B. Ramos ${ }^{\mathrm{a}, *}$, Sandra Caeiro ${ }^{\mathrm{b}}$

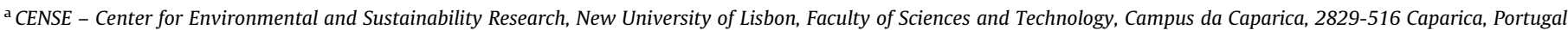

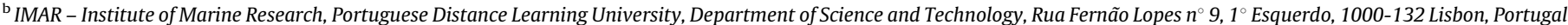

\section{A R T I C L E I N F O}

\section{Article history:}

Received 9 October 2008

Received in revised form 19 April 2009

Accepted 22 April 2009

\section{Keywords:}

Sustainable development

Environmental

Indicators

Meta-evaluation

Performance

Validation

\begin{abstract}
A B S T R A C T
There are many different kinds of frameworks for evaluating environmental and sustainability performance at the organizational level (profit or not-for-profit, private or public), sectoral level (e.g. industry, transport, agriculture and tourism), and local, regional or country levels. Despite the diversity of methods and tools to measure sustainable development, indicators are one of the approaches most used. However, these tools do not usually include evaluation of the performance measurement instrument itself. The main objective of this research is to develop a conceptual framework to design and assess the effectiveness of the sustainability indicators themselves. To put the proposed tool into practice, a set of key good-practice factors and meta-performance evaluation indicators is proposed for adoption in a national case study-the national sustainable development indicators system, SIDS Portugal, and the usefulness of this methodology is demonstrated. This approach aims to evaluate how appropriate a set of sustainability indicators is and allow an evaluation of overall performancemonitoring activities and results. Stakeholder involvement is an essential component of the proposed framework. The tool developed could support continuous improvement in the performance of ongoing sustainability indicator initiatives, allowing greater guidance, objectivity and transparency in sustainability assessment processes.
\end{abstract}

(c) 2009 Elsevier Ltd. All rights reserved.

\section{Introduction}

The concept of sustainable development is charged with complexities as it involves and balances several different goals, content types, approaches, aspirations and desires. If it is to be analysed and carried out on the basis of a decision-making process, sustainability must be measured. There are many ways to measure sustainable development, each of which provides potentially useful, though different, insights for policy makers, academics and the general public. As a multifaceted concept, sustainability requires aggregate measures (Hanley et al., 1999), based on the integration of the different sustainability domains, that in due course define whether a system is sustainable or not. Methods of sustainability development evaluation have proliferated during the last few years. However, they are often time-consuming and expensive to conduct, making reiteration, a crucial part of the assessment process, an unappealing and difficult task. Making the results comprehensible and meaningful to the public is also challenging but essential if evaluations are to be translated into policy and action (Becker, 2004). According to Ness et al. (2007), sustainability assessment tools should respond positively to three questions: are the tools capable of

\footnotetext{
* Corresponding author. Tel.: +351 212948397; fax: +351 212948554

E-mail address: tabr@fct.unl.pt (T.B. Ramos).
}

integrating nature-society systems? Is the tool capable of assessing different scales or spatial levels? Are the tools able to address both the short and long-term perspectives?

As succinctly summarised by Singh et al. (2009) and Wilson et al. (2007), two distinct methodologies can be used to assess sustainability: weak sustainability and strong sustainability measures, where the first assumes perfect substitutability between produced and natural capital and the second assumes no substitutability. According to ecological economic perspective there are a number of services of nature that cannot, even in principle, be replaced by man-made capital or human labor. This is the essence of what is meant by strong sustainability (Ayres, 2008). Sustainability indicators can follow one of these two approaches, depending on the understating of "development", growth and sustainability. In fact, indicators are one of the approaches most often used to evaluate sustainable development. The argument of weak and strong sustainability is sometimes seen as a discussion between (neoclassical) environmental economics and ecological economics. While the former branch of economics assumes substitutability between natural and man-made capital, and optimism towards future technologies developing out of increased prices for environmental inputs, ecological economics usually prefers physical (strong) sustainability indicators (Getzner, 1999).

Sustainable development indicators (SDIs) are used to collect, process, and use information with the goal of making better 
decisions, directing smarter policy choices, measuring progress, and monitoring feedback mechanisms, as emphasized in the United Nations Conference on Environmental and Development, held in Rio de Janeiro in 1992 (Agenda 21, Chapter 40). Though the adoption of indicators helps in the analysis of many types of information, evaluation, as a process, allows the use of measures to drive policies, through the implementation of concrete and effective improvement plans, provided that they respond to the strengths and weaknesses emerging from the analysis of the indicators (Scipioni et al., 2008).

The Bellagio Principles are a practical set of guidelines for the development and use of SDIs. According to these principles, assessment of progress toward sustainable development should be guided by a clear vision of sustainable development and goals that define that vision. The assessment should reflect a holistic view of the linkage between social, environmental and economic considerations and it should have the appropriate scope while still offering a practical application. The process of developing the assessment tool should be open and inclusive with effective communication and broad participation; it should be a continuous, iterative and adaptive process that provides ongoing support in the decision-making process (Hardi and Zand, 1997).

A significant advantage of SDIs is their increased accuracy in evaluating/quantifying the different sustainability issues under consideration since these issues need to be translated to other metrics (Gasparatos et al., 2008). In current practice, indicators are often selected either on the basis of historical practices and regulations or expert knowledge and the degree to which, individually, they meet a number of criteria (Niemeijer and Groot, 2008). In this way indicators and indices, which are continuously measured and calculated, allow for the tracking of longer term sustainability trends from a retrospective point of view (Ness et al., 2007).

Although there are well known indicator selection criteria and it has been well over a decade since Agenda 21 first called for sustainability indicators, SDIs have not yet fully matured and little effort has been put into their validation (Bockstaller and Girardin, 2003; Meul et al., 2009), in particular into evaluating how, jointly, as a framework, they respond to sustainability questions, from the standpoint of a meta-evaluation and/or sensitivity analysis. It is important, therefore, to question the effectiveness of SDIs in an effort to continue advancing and facilitating sustainability (Wilson et al., 2007) and to illustrate to what degree the outcomes achieved correspond to the goals intended (Lyytimäki and Rosenström, 2007). In this way validation verifies whether the indicator possesses a degree of "accuracy" consistent with its intended application and a degree of "credibility" conducive to the potential users' confidence in it and the information derived from it, and hence their willingness to use it (Meul et al., 2009). In fact, validation means the achievement of overall objectives or the production of the intended effects, but as pointed out by Bockstaller and Girardin (2003), the use of any evaluation tools should be formalised in a real test and not simply limited to a descriptive work. A key component of effective evaluation is how information is presented, which will depend on the purpose of the evaluation, the target audience, and their familiarity with the information. Simplification of the results is a key factor (Becker, 2004).

Meta-evaluation is not a new concept and in fact it was initiated by Scriven (1969). Meta-evaluation is an evaluation of an evaluation. It is a critical assessment of the strengths and weaknesses of an evaluation, and draws conclusions about its overall utility, accuracy, validity, feasibility and propriety. Metaevaluation can serve a valuable function as a self-assessment quality-control tool during the implementation of an evaluation. It could use methods such as a checklist to help the evaluator to be sure that nothing important has been missed out (Patel, 2002).
Meta-evaluation within some environmental and sustainability assessment tools or instruments is more mature than others. Environmental impact assessment (EIA) and strategic environmental assessment (SEA), as stressed by Gasparatos et al. (2008), are some good examples of that tools that are submitted to a review process through a meta-evaluation analysis. Ex-post evaluation of these tools refers to a generic process of review, analysis and interpretation of all aspects of EIA and SEA effectiveness and performance, encompassing the process both as a whole and in terms of its components, methods, procedures, activities, products and results-and their policy and institutional implications (Sadler, 2004).

Sensitivity analysis is a more common issue within composite environmental or sustainability performance indicators or indices (e.g. Kang, 2002; Singh et al., 2007), due to the fact that mathematical models are associated with them, where validation processes are usually conducted. But sensitivity analysis can also be computed to highlight the most important indicators that promote or avoid progress toward sustainable development within different scenarios which largely reflect the results of policies and actions taken in a particular period, as in the work of Andriantiatsaholiniaina et al. (2004), using fuzzy logic reasoning.

The main objective of this research is to develop a conceptual framework to design and assess the effectiveness of the sustainability indicators, which do not usually include an evaluation of themselves. A set of key-factor and meta-performance indicators is proposed for adoption in a national case study-the national SDI system, SIDS Portugal: it shows how appropriate the sustainability indicators are and allows an evaluation of overall performancemonitoring activities and results.

It is not the purpose of this work to analyse the metaperformance of all the different kinds of sustainability assessment methodologies and tools or - even less - to criticise and to offer a critical comparison of the way various instruments on sustainability assessment perform (e.g. Singh et al., 2009; Gasparatos et al., 2008; Ness et al., 2007; Parris and Kate, 2003).

\section{An overview of the meta-performance evaluation of sustainability indicator initiatives}

Some work has been carried out to evaluate the performance of developed environmental and sustainability indicators and indices. For example, Jackson et al. (2000), Kurtz et al. (2001), Bockstaller and Girardin (2003) and Meul et al. (2009) have developed methodologies to evaluate ecological/environmental indicators, where end-users play an important role in determining indicator applicability or effectiveness. Cloquell-Ballester et al. (2006) have developed methodologies for the validation of indicators within the environmental impact assessment of project studies, where the core of the validation is to access the correct performance of new indicators in terms of concept, coherence, operational coherence and utility. Other studies have compared several national sustainable development index metrics, evaluating their consistency and meaningfulness (Böhringer and Jochem, 2007; Wilson et al., 2007).

These different works try to meta-evaluate composite sustainability indicators/indices or environmental/ecological indicators, but virtually none try to meta-evaluate SDI systems as a whole. They mainly focus on a sensitivity analysis of the mathematical algorithms that support indices or on more particular thematic tools or domains such as EIA or ecological indicators.

Despite the proliferation of sustainability indicator frameworks, mainly implemented at the country level, few of these frameworks include meta-evaluation procedures and, to even lesser extent, indicators to operate this kind of analysis. Even though national experience of SDI frameworks, e.g. that of Spain 


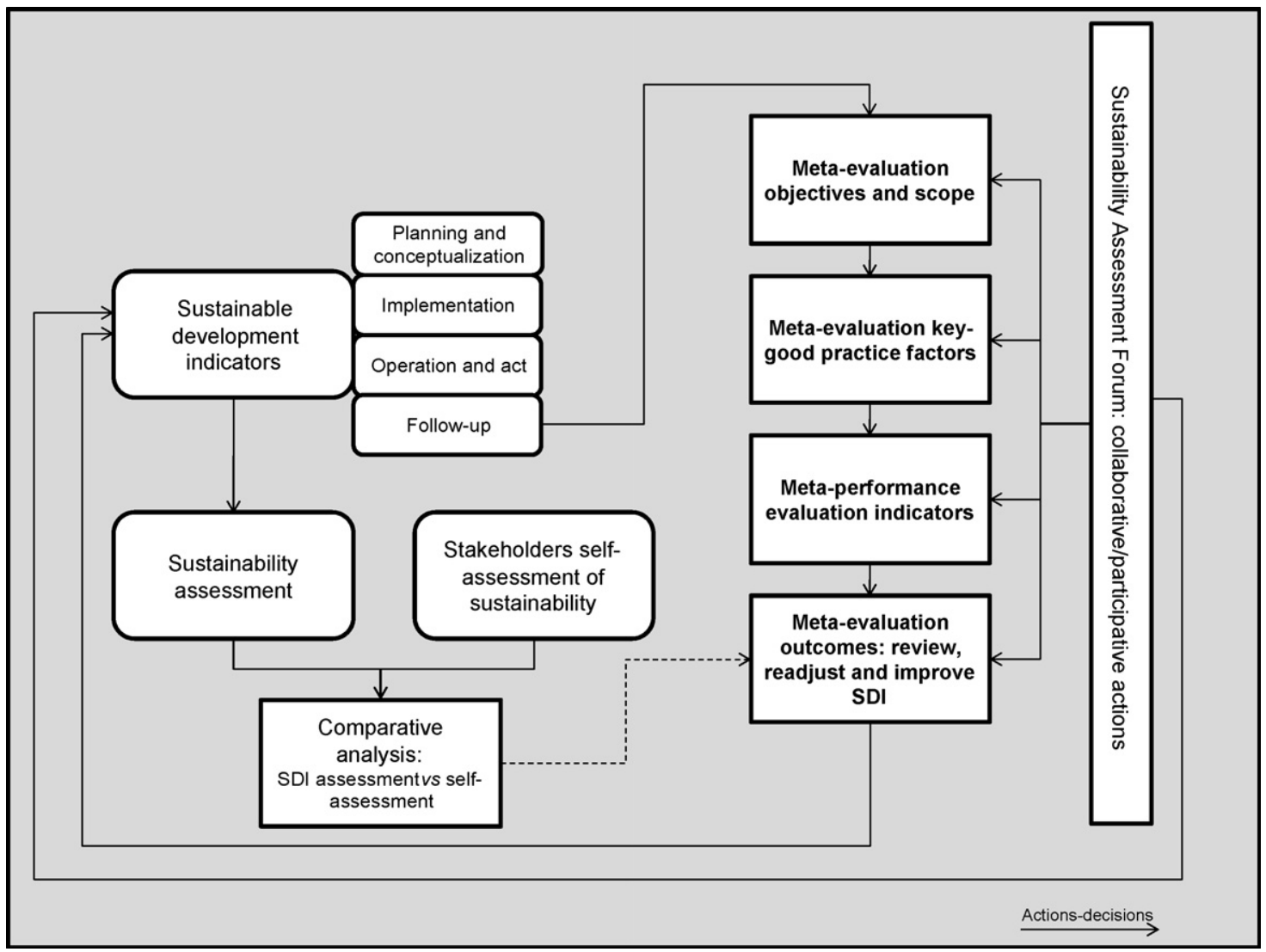

Fig. 1. Conceptual framework for meta-performance evaluation of sustainability indicators.

(Gallego, 2006), Germany (Walz, 2000) and Finland (Rosenström and Kyllönen, 2007) considers the requirements of indicator selection, including public participation approaches to support SDI development, it does not include meta-evaluation of the SDI systems themselves or their components, procedures and indicator outcomes and impacts.

Lyytimäki and Rosenström (2007) analyse the effectiveness of different national conceptual frameworks for communicating SDIs in Finland and concluded that it is important to pay more attention to the indicators as a set than on an individual basis and that specifically tailored frameworks should be employed for specific uses. According to these authors, it is easy to list the characteristics of an ideal framework, but not so easy to find frameworks that actually contain these ideal characteristics. The same situation applies to stipulating and implementing the criteria for individual indicators. When a comprehensive list of ideal characteristics has been compiled, it is left for someone else to come up with actual work that meets all these criteria. In addition, a long list of indicators or extensive frameworks may be introduced that fail to meet the criteria. Monitoring and evaluating how indicators are used and learning from the information acquired are at least as important as the development work aimed at improving the ability of a framework to depict the reality objectively. This may be considered the key challenge for future research on SD frameworks and indicators (Lyytimäki and Rosenström, 2007).

\section{Development of the conceptual meta-performance evaluation framework}

This paper assumes a definition of sustainability metaperformance evaluation that is supported by the concept presented in Ramos et al. (2007b), as applied to public sector environmental performance evaluation. This is a tool to assess the effectiveness of the sustainability assessment instruments themselves, where indicators are one of the most widely used and wellknown tools. Meta-performance is understood here as part of performance management and assessment procedures. Sustainability meta-performance evaluation indicators could be the practical instruments for verifying the assessment, in showing how appropriate the SDIs are and allowing an evaluation of the overall performance of the assessment processes and results.

The sustainability indicator system itself, the entire structure of the indicators and the methodological features of the latter will be the target of the meta-performance evaluation process. Metaperformance evaluation indicators show the following: (i) an evaluation of overall assessment activities, to measure how well the indicator initiative is going; (ii) the appropriacy of the sustainability indicators, including the methodological aspects and outcomes produced and (iii) an evaluation of the sustainability measures and actions originated by the indicator operation and analysis.

A framework to conduct meta-performance evaluation of sustainability indicators was developed with the aim of identifying how to put the sustainability meta-evaluation challenges into practice (Fig. 1). This framework was designed to be potentially applied to national, regional and local SDI initiatives, supporting indicator validation and allowing continuous assessment of these tools. Meta-evaluation may be seen as one process or component within an entire SDI system, mainly aimed at indicator revision and updating and system improvement. The development of sustainability indicators, when analysed as a system where different processes occur, includes a series of actions and decisions with various data and information flows. Approaches to sustainability indicators should define various principal components, to assure a coherent development process. They may be divided into the following main categories: 
(i) Planning and conceptualization (including all the design components and processes);

(ii) implementation: the whole process of data collection, processing and analysis;

(iii) operation and action: outcomes are presented through reporting and communication tools, leading to different kinds of reaction (e.g. policy measures; stakeholder participation); establishment of flow links with other SDIs, at the local, regional, national and international levels, and with strategic tools/instruments (policies, plans or programmes);

(iv) follow-up: updating and reviewing, mainly based on a metaperformance evaluation process.

This framework seeks to incorporate a systems analysis approach that integrates the main relationships among different components of the meta-performance evaluation of sustainability indicators.

As with any planning or management process, SDI systems should be flexible and dynamic, and should have a follow-up procedure for reviewing and monitoring, and improving the robustness and overall quality of the sustainability assessment results produced by the indicators.

The procedure for the meta-performance evaluation of sustainability indicators starts with a definition of the main objectives and the scope of this process, which will depend on various fundamentals that characterize the SDI system and its indicators. On the basis of current and well-established principles and guidelines for environmental and sustainability indicator development, key good-practice factors should be selected in order to develop a tool that can be operationalized through the construction of a checklist and the corresponding meta-performance evaluation indicators. These factors will cover two main levels of evaluation:

- Performance of the SDI system, including the main processes, and the respective actors and methodological approaches;

- performance of individual and aggregate indicators, including their inputs, outputs and outcomes/impacts.

The key good-practice factors of meta-evaluation should include various aspects, e.g. the type of SDI management framework, the existence of some sort of collaborative/participative process, the target audience, the coverage of the subject, the structure of the indicator organization (e.g. sustainability dimensions/themes and/or causal chain frameworks, such as the STRESS model (Rapport and Friend, 1979) from which the OECD (1993) pressure-state-response (PSR) framework was developed), the number of indicators, the relationship with sustainability indicators developed at different levels (national, regional, local and organizational), the regularity of the reporting, the sustainability indices, and the indicator report format/platform (the medium used to communicate the report information). In this way, metaevaluation outcomes can be obtained and the reviewing process implemented, with readjustments and improvements to the SDIs through an adaptive scheme.

Public participation should run through the entire design and development of an SDI system, playing a decisive role in the credibility, transparency and robustness of the initiative. This participative process should occur with greater significance in certain phases of the process, particularly in the scoping of thematic priority areas and in indicator selection/validation. Restricted sectoral meetings involving invited private and public organizations and workshops involving a wide audience of key stakeholders are some of the initiatives that can support this participatory approach. As stressed by Gasparatos et al. (2008), for the assessment of the progress towards sustainability, participatory sustainability assessment frameworks should be used. Most of the works listed earlier, in Section 2, also used participation processes to validate indicators (Jackson et al., 2000; Walz, 2000; Kurtz et al., 2001; Bockstaller and Girardin, 2003; Gallego, 2006; Cloquell-Ballester et al., 2006; Rosenström and Kyllönen, 2007; Meul et al., 2009).

In the course of the stakeholders' involvement in the SDI development, a stakeholder survey relating to the self-assessment of sustainability could also be carried out. The results of the stakeholders' own assessment of sustainability performance will be used to make a qualitative comparative analysis with the formal sustainability assessment that will be provided by the SDI. The stakeholders' assessment of sustainability can also be used as an indirect way of complementing the meta-performance evaluation results. The results of the comparison will be used for crossvalidation of the sustainability meta-evaluation outcomes. The credibility of sustainability self-assessment and the related procedures and outcomes analysis is a relatively under-explored issue, but it could be of particular importance for this kind of analysis.

A Sustainability Assessment Forum for monitoring surveillance and revision of the SDIs will guarantee a collaborative/participative meta-performance evaluation process. This structure should include key stakeholders (experts and non-experts), in particular public and private organizations responsible for data collection, non-governmental organizations, universities and research institutions, with regard to each sustainability indicator or group of indicators. Thus, the forum will have a leading role centered on active participation in SDI development, operation and follow-up, but also on the updating and revision processes. This collaborative/ participative component of the meta-performance evaluation of sustainability indicators is divided into two levels:

- Overall follow-up of the meta-evaluation procedures, including the impact on the sustainability indicator system and respective measures for SDI readjustments and improvements. This procedure could be supported by an e-mail list to provide feedback and by two collaborative meetings (the first to identify objectives and delimit, analyse and prioritize the scope of the most important key-factor and meta-performance indicators and the second to analyse the meta-evaluation outcomes and their implications);

- a questionnaire survey of end-users and/or sectoral meetings to validate the SDI indicators and propose changes.

This framework was designed to improve the quality of indicators, by facilitating their development and evaluation, and produce better sustainability assessments. As stressed by Kurtz et al. (2001), this kind of approach can be used to target gaps in knowledge and formulate future research directions.

When a list of good-practice factors has been obtained, a scoring procedure can be used to obtain the overall performance level. To avoid a too complex and resource-demanding process, the list of factors could be scored according to a qualitative assessment, based on expert knowledge, of how well the SDI system or indicator meets the requirements. An ordinal scale based on five categories can be defined to classify each meta-performance evaluation factor, in a range from 1 to 3 : poor -1 ; medium-2, good-3. The aggregated and final result value can be computed using an arithmetic or heuristic algorithm. As an alternative or complement to the scoring method, a summary analysis taking in each specific key factor could be also conducted to produce a qualitative integration of the main meta-evaluation outcomes. This analysis could help to mitigate the reductionism that characterizes this scoring approach. As stated by Gasparatos 
et al. (2008), the emergence of post-normal science (Funtowicz and Ravetz, 1993) and the belief that it is essential to describe complex systems through the synthesis of their different, non-reducible and perfectly legitimate perspectives (Funtowicz and Ravetz, 1994) adds yet more to the discontent over the validity of reductionism in sustainability assessment, as with that arising from the use of indicators and metrics.

The proposed meta-performance evaluation framework will not directly measure the full real outcome or value of a certain SDI system in assessing sustainability, given the complexity and uncertainty of sustainability issues. Nevertheless, it will help the user to ascertain if the indicator initiative is well developed, implemented and managed, and will give important signals about the credibility and accuracy of the SDI set.

\section{Meta-performance evaluation of the Portuguese SDI system}

\subsection{SIDS Portugal}

In the year 2000 the Portuguese Ministry of the Environment and Land-Use Management published the first edition of the national SDI system - SIDS Portugal, using the Portuguese acronym - following an initiative started in 1997 (DGA, 2000). A set of 132 SDIs, covering economic (29), environmental (72), social (22) and institutional (9) dimensions, was developed using the PSR framework and the indicators proposed by the United Nations (1996).

In most European Union Member States, the development of national sets of SDIs is expressly linked to the drafting of national SD strategies and the formulation of SDI sets is frequently intended to facilitate measurement of the degree to which the strategies' aims and objectives are being achieved. The principal exceptions are Portugal and Sweden, which both developed an initial version of SDI sets prior to their SD strategy (EC, 2004).

Recently, the Portuguese SDI was updated and a new edition was published (APA, 2008). Under the scientific coordination of the New University of Lisbon, a renewed methodological approach was developed (Ramos et al., 2007a), aiming at an improvement in the previous work and a definition of guidelines for future editions. The indicators in this new SDI version clearly reflect links with the Portuguese SD strategy (published in 2006). However, the indicator system has not been formally incorporated into official government policy as a monitoring tool of the SD strategy.

\subsubsection{Objectives}

The main objective of SIDS Portugal is to assess and report the levels of sustainability in the country. It aims to contribute to improving the management of environmental, economic, social and institutional performance, and to inject greater efficiency into the synthesis and exchange processes for sustainable development information. Two of the specific SIDS targets are: (i) to provide a broad basis of SDIs and (ii) to support the monitoring of the main strategic instruments for the country's sustainable development, and thus help to assess fulfilment of the goals and targets set for policies, plans and programmes.

The target audience is all stakeholders in the assessment and reporting of sustainability and the particular emphasis is on headline indicators for the general public, decision-makers and managers. Wherever possible non-technical language or, alternatively, graphics are used to facilitate dissemination, particularly in the case of headline indicators.

\subsubsection{Management framework}

The institution in charge of SIDS Portugal management is the National Environmental Agency (APA, using the Portuguese acronym), the national institution responsible for assessing and reporting on the environment and sustainability.
In order to ensure that the indicators are the result of an open model, with participation and validation, SIDS has the support of an institutional network that includes several public sectoral agencies, mostly working at a distance. They have the capacity to monitor and intervene in all phases of the development process, in particular the evaluation, communication and review of indicators and their associated information. It is planned that this network will be enlarged to be representative of the key stakeholders involved in environmental and sustainable development assessment and communication to ensure that all thematic aspects or sectors relating to SIDS will be fully covered, including experts by each indicator or by similar groups of indicators.

\subsubsection{Indicator structure/organization}

The indicator structure is distributed over various types of sustainability themes. ${ }^{1}$ The lists of topics were selected and developed in order to maximize two conditions: (i) comparability with other similar SDI systems, particularly in the context of the European Union, and (ii) communication with all stakeholders. The themes seek to cover areas that have political relevance, especially those that exist in strategic documents. In addition, the indicators are classified in accordance with the DPSIR conceptual model (RIVM, 1995; RIVM/UNEP, 1997), which is widely adopted at the European level and includes the following categories: driving forces, pressures, state, impacts and responses.

The core set of SDIs has decreased to 118 indicators since the earlier version; it now covers economic (36), environmental (36), social (36) and institutional (10) dimensions, plus two new indicator subsets that have been defined: 30 headline indicators and 30 common regional indicators. This common indicator subset, which is "the minimum common denominator" for the regions, allows regional sustainability benchmarking among regions and enhances the analyses of asymmetries. The headline indicators are a sub-domain of the core set of SDIs destined to communicate with decision-makers and the general public, and to report often. The regional indicators are also a sub-domain of the core set of SDIs, partly coincident with the headline set.

To obtain the set of published indicators various specialised institutional meetings/questionnaires involving different public sectoral organisations were held. The representatives of the regional agencies also participated in those surveys, which meant that the proposal for national sustainability indicators could act as an important driving force in encouraging the regions to develop similar approaches for their territories.

\subsubsection{Regularity - the frequency of reporting - and the review process}

SIDS Portugal will report on the complete list of indicators (118) every 4 years and the subset of headline indicators will be available annually. A complete sustainability indicator process and methodological review should take place 8 years after the formal publication of the final version, except in particular situations where it proves necessary to introduce significant methodological changes. The methodological approach of this indicator system underlines the fact that a formal meta-evaluation stage should be adopted to support the review process.

\subsubsection{Promotion and communication}

The full version of SIDS Portugal is available on paper and in electronic format (PDF - Adobe Portable Document Format -

\footnotetext{
${ }^{1}$ Indicators are organized into 27 thematic areas: economy, tourism, transport, energy, industry, agriculture, forestry, fisheries, employment, science and technology, law, education, governance, population, cohesion/social exclusion, international cooperation, health, culture, air and climate, water, nature and biodiversity, risks, soils and land use planning, marine and coastal environment, waste and environmental management tools.
} 
Table 1

Key good-practice factors and meta-performance evaluation indicators for sustainability assessment.

Key good-practice factors Summary of rationale/recommendations

Lbjective, scope and scale effects (scale integration and spatial extent)

Target audience and type of language

Management model and institutional cooperation

Technical and educational skills of the staff

Indicator organization and structuring

Regularity issues, revision and updating procedures

Governance and public participation process indicator sets. be achieved. should be clearly stated.
Identifying general and specific objectives for the sustainability assessment purposes, stressing the territory characteristics and the scope of the analysis. SDI objectives should be linked with strategic tools and instruments and cover the main dimensions of SD. If themes and sub-themes are well delimited, integrating the results of public participation processes, the risk of missing important issues can be minimized. As stressed by Mitchell (1996), the SDI development programme should recognise sustainability principles and limits and should focus on the objectives of the indicators and the user group. Vertical integration among national, regional and local SDI systems should be reflected in the selected

Clear identification of the various principal types of target audience to be reached and the corresponding preferred language (technical/non-technical) in the indicator system. The target end-users and the respective requirements and realities should be considered in the SDI design and operation. SDI systems are frequently developed to satisfy multi-audience aspirations. It is also essential to give a clear definition of the central indicator audience, as it can limit the overall assessment and reporting structure. The SDI system should at least clarify if it intends to reach only or mainly non-technical audiences.

The definition of the management framework should be clearly defined. The institution(s) and their roles and the leadership structures are essential to an understanding of the feasibility and societal influence of the SDI system. Establishment of institutional cooperation agreements/protocols at the national, regional, local and international/transboundary levels. These institutions could include other public agencies, foreign organizations, NGOs and universities. Academia or research institutions could have a formal and active role.

The staff's educational background should reflect multidisciplinary visions to fulfil the needs of the broad nature of sustainability related subjects. If the agency and team responsible for the development and management of the SDI system have a significant interaction with external partners (e.g. other public agencies, academia, non-governmental organizations and business) more benefits can

Despite the lack of international consensus on the number and type of indicators or the framework or conceptual model that should be used, indicator organization and structuring is a fundamental issue. To what extent does the SDI system fit into a coherent conceptual framework? How are sustainability indicators organized to better achieve the objectives? By dimension of sustainability, by theme or subtheme on the basis of causality chains (e.g. pressure-state-response) or according to another structural scheme? Independently of the structuring scheme, the SDI system should clearly explain how indicators are organized and present the explanation for that choice. The indicators, in total, by group or by category, should reflect the objective and scope of the SDI system, representing equilibrium among the different components, and be manageable. The clear identification and use of headline indicators could contribute to improving communication with decision-makers and the general public

The SDI system must identify the frequency of reporting and review the whole system, independently of continuous partial reviews and updates. Revision and updating of the SDI system, including the definition of procedures or criteria to assess the effectiveness of the process and sustainability indicators themselves

SDI system should integrate good governance practices. The European Commission defines five principles of good governance: "openness, participation, accountability, effectiveness and coherence" which are of particular significance in sustainability assessments. Factors like territorial languages and cultural patterns and values should be integrated into the participatory and interactive processes. The promotion of dynamic interaction among all stakeholders should exist from the beginning of the process. It should be supported by participative and collaborative procedures, where different actors can play important roles, improving capacity building and assuring transparency, credibility and robustness, beyond the strict, predetermined, technical and scientific tasks. The design, construction, operation and revision of the indicators can also be submitted to a panel of experts, in accordance with expert consensus practices, for instance by means of the Delphi technique. This panel can work before and after the SDI has been implemented.
Meta-performance evaluation indicators

(checklist examples): name and

measurement units/scale (in brackets)

Main dimensions covered by the SDI system: environmental economic, social and institutional (yes, no, not clear, for each SD dimension) Themes related to particular territorial featuresnational, regional or local, depending on the main SDI scale (\%; no.)

Indicators for comparison/integration among different spatial scales (type and no.)

Identification of the central indicator audience (yes, no, not clear)

Identification of the management model (yes, no, not clear)

Institutions involvement and cooperation

(type and number of institutions and their roles)

Staff profile: type and diversity of staff (total number of personnel; no. per type of background or expertise; number of personnel by function and time spent)

Training personnel for particular indicator tasks (number of persons allocated to SDI development who follow training initiatives)

Use of a conceptual framework - by sustainable development dimension or theme, DPSIR, PSR or others - for SDI organization and structuring (yes, no, not clear)

SDI size (total no. and no. by type)

Indicator subsets (type of indicator subsets for particular purposes, e.g. headline indicators; common regional or local indicators)

Revision of the entire SDI system processes including a review of the general methodological approach and related procedures as well as a reselection of the indicators (yes, no, not clear; no. of revisions planned versus accomplished) Regular SDI updating and reporting (yes, no, not clear; no. reports and updates planned versus accomplished)

Participative/collaborative processes undertaken in each stage of the SDI development, from the design to the operation and revision stages (yes, no, not clear; total no. and type of stakeholders involved in each participative phase) Stakeholders' feedback to SDI development (no. year $^{-1}$ of messages received by e-mail/letter or through personal contacts)

Institutional cooperation with other public institutions for SDI development and implementation (yes, no, not clear; no. of formal and informal protocols) 
Table 1 (Continued)

\begin{tabular}{ll}
\hline Key good-practice factors & Summary of rationale/recommendations \\
& \\
\hline $\begin{array}{l}\text { Relationships with } \\
\text { regional strategies }\end{array}$ & $\begin{array}{l}\text { These initiatives should be associated with Sustainable Development Strategies } \\
\text { (SDS) or with other important strategic instruments, when an SDS does not exist. } \\
\text { The SDI system could also act as a main menu from which to choose indicators } \\
\text { that could be used for policies, plans, programmes or projects (e.g. the monitoring } \\
\text { of strategy and plan objectives and actions; strategic environmental assessment; } \\
\text { environmental impact assessment processes). }\end{array}$
\end{tabular}

Intra-territorial asymmetries

Communication and

Cost-benefit analysis stakeholders' responses promotion/dissemination
Sustainability assessment tools should provide the evaluation of internal territorial asymmetries-use of particular methodological approaches, supported by relevant sustainability indicators, to analyse inequities or disparities among smaller territories within the assessed domain.

The communication strategy of SDI should be clearly established to maximize the usefulness of the SDI system reaching the end-users. The communication and reporting platforms, aiming at improvement in the communication with decisionmakers and the general public, could be put into practice using several instruments, e.g. internet sites, brochures, books, seminars and workshops.

Cost-benefit analysis involving the examination of a decision in terms of its consequences or costs and benefits will provide a consistent procedure for evaluating the implementation of SDIs in terms of their outcomes/ impacts, along the same lines as an evaluation of a public sector project.

The responses to the sustainability assessment results provided by indicators are one of the main challenges. Policy and management decisions, as well as society actions, through recommendations and specific measures will seek to improve sustainability levels, through a continuous process. Sustainability indicators should provide linkages with policy monitoring indicators, particularly output and outcome indicators for policies, plans and programmes.
Meta-performance evaluation indicators

(checklist examples): name and measurement units/scale (in brackets)

SDS goals and objectives covered by the sustainability indicators (yes, no, not clear; no.;\%)

Use of particular methodological procedures to measure territorial asymmetries

(yes, no, not clear)

Reporting and communication to stakeholders (no. reports, workshops, internet sites, e-mail list)

Implementation of public sector projects as outcome of SDI results (no. year ${ }^{-1}$ )

SDI planning/conceptualization and maintenance investments and expenses

$\left(10^{3} €\right.$ indicator $^{-1}$ year $\left.^{-1}\right)$

Linkage between sustainability indicators and output and outcome indicators for policies, plans and programmes (yes, no, not clear) Decisions, actions/recommendations and measures to reverse or prevent negative trends and to maintain or increase positive trends (\%; no. by type of sector) Identification of unexpected sustainability effects through the SDI measurements (\%; no.) Willingness of potential end-users to effectively use the SDI systems (\% of positive answers from potential end-users submitted to an interview survey)

Indicators that are not supported in published scientific or technical work (no.; \%)

Stakeholders that use the indicator in their sectoral activity assessment (no.; \%) Direct relationships between the indicator title and its category (yes, no, not clear; no.;\%) Indicator targets reached (no.)

targets and sustain use/need a certain indicator for their sectoral activity assessment.

category, theme and/ or sub-theme and bear on a fundamental process or widespread change. Ability to provide a representative and integrated picture of significant sustainability dimensions: economic, social, environmental and institutional. The proposed indicator must be responsive to an identified assessment question or multiple questions, providing useful information for overall end-users and in particular decision-makers. The definition of the indicator and the concepts that make it up should fit into the SDI system, and their interpretation and meaning should cover key aspects/components/ gradients and have the capability to summarise the results.

It must be demonstrated that the indicator reflects the classification attributed through a conceptual category (e.g. causal chain categories), theme or sub-theme. Sectoral stakeholders must demonstrate that they Indicator should have the capacity to give early warning about irreversible trends, responsiveness to changes in sustainability levels, and related pressures-within policy time-frames. To support sustainability assessment, with the aim of more objectivity and transparency, targets/thresholds should be provided for each indicator. There should be a target level or threshold against which to compare the indicator so that users are able to assess the significance of the values associated with it. Targets/thresholds could be based on policy targets, legal mandatory values, existing historical records of comparative data, baseline or reference values, benchmarks or scientific/technical reference values. This will help indicator interpretation by stakeholders, promote commitment and facilitate decision-making processes.

Methodological approaches for data collection and analysis
Methods for data collection and analysis should be described. The data used in the indicators and its unit should be suitable, consistent and reliable, and the proposed measurement procedures to obtain the indicator should allow its reproduction and comparison. Standard, certified or internationally well-accepted methods are preferred. Indicators should have existing data readily available and not require excessive data collection skills and should have the ability to be updated at regular intervals The operability of the determination method is also of particular importance. The mathematical formulation of the indicators should be appropriate to the concept to be quantified. Environmentally friendly products and equipment should also be used for data collection and analysis and there should be minimal environmental impact from the sampling process itself.
Indicators without clear methods of data analysis and/or collection (no.; \%) Periodicity of new data collection for indicators (no.;\%);

Chemical use in indicator data-collection activities (loads of monitoring reagents reaching environment: indicator ${ }^{-1}$ year $^{-1}$ )

Use of environmentally preferable products and equipment in indicator measurement (no. of environmentally preferable products: indicator ${ }^{-1}$ year $^{-1}$ ) 
Table 1 (Continued)

\begin{tabular}{ll}
\hline Key good-practice factors & Summary of rationale/recommendations \\
\hline Quality control & $\begin{array}{l}\text { It is necessary to be able to ascertain the degree of accuracy/uncertainty for each } \\
\text { indicator. Data quality control is a fundamental step in ensuring the desired } \\
\text { validity. A quality assurance plan should identify the quality objectives for each } \\
\text { step in the data collection and processing. Means and methods to audit the } \\
\text { quality of each step should be also identified. Each indicator must meet the } \\
\text { respective quality targets. }\end{array}$
\end{tabular}

Spatial and temporal scales Scale effects can have significant importance on sustainability assessments. Therefore, the appropriateness of the scales is important for the accuracy of the indicator. Temporal and spatial variability can also have significant implications for indicator data collection, processing and analysis. The optimal time frame should be identified and spatial units of analysis should also be pointed out. The recommended scope, in time and space, to guide data collection, processing and analysis; particular spatial units may be taken into account (e.g. socio-economic and/or homogeneous biogeographical areas). Scale choice can therefore have important repercussions on the accuracy of the indicator. The use of spatial technologies (like GIS) and the definition of homogeneous spatial units could be are options for information desegregation and analysis.

Logistical requirements and information management

Costs

Understanding and social utility
Sustainability indicators that are particularly time, material and energy consuming or personnel intensive, among other considerations, should be carefully evaluated against the indicator system objectives. The logistics requirements should be defined/estimated, including the time required to collect, analyse and report/ communicate the data. Indicators should be simple to measure, manage and analyse, and achievable in terms of the resources and time available. Information produced by each indicator should be properly managed, including at the data processing, analysis and storage stages. All this information should be provided for each indicator, supported by a clear logistics and information management procedure.

The costs of indicator implementation and operation should be estimated and evaluated. Each indicator should demonstrate a reasonable cost/benefit ratio, since cost could be a significant barrier to maintaining an existing indicator or adding a new one.

The output of the indicator should be understandable or interpretable. The social valuation of the indicator by stakeholders is an aspect of particular importance for sustainability assessment. Efforts to develop a process for translating sustainability indicator results into common language for communication with the public and decision-making audiences, as explored by Schiller et al. (2001) for ecological indicators, could be a fundamental step in communicating scientific information to non-technical audiences, and representing societal values in sustainability strategies, as stressed by those authors. Simplicity, ease of interpretation and ability to show trends over time are fundamental properties for the attainment of good indicator performance. Their usefulness in communicating with and reporting to a wide audience should be assured. A survey can be conducted in which potential users can point out the strengths and weaknesses of the SDI. Such a survey can also be helpful to ensure that end-users understand what is being indicated and to check whether the results are interpreted correctly. Interviews can be used to obtain specific information from a sample of a population, to obtain general information relevant to specific issues and to gain a range of insights into specific issues.
Meta-performance evaluation indicators

(checklist examples): name and

measurement units/scale (in brackets)

Identification of quality control objectives for each indicator (yes, no, not clear)

Identification of the means and methods to audit indicator quality (yes, no, not clear) Analytical measurements and related detection levels (no. of indicator measurements under analytical detection level year ${ }^{-1}$ )

Indicators within socio-economic and/or homogeneous spatial/biogeographical units (no.; \%)

Identification of logistics requirements for each indicator (yes, no, not clear) Identification of information management procedures for each indicator (yes, no, not clear)

Average cost of sustainability indicators $\left(10^{3} €\right.$ indicator $^{-1}$ year $\left.^{-1}\right)$

Indicators easily understandable by the end-users (no.; \% of positive answers from potential end-users submitted to a survey) . (including all their content, e.g. the main indicator structure, data flows and institutional actors) were used to design the list of factors and indicators. The experience acquired (strengths and weaknesses) with this national SDI system, from the beginning of its operation in 2000 , was also taken into account to operationalize the conceptual framework for meta-performance evaluation.

A great amount of work already published presents the ideal criteria to select and develop environmental and sustainability indicators, in particular the Bellagio Principles (Hardi and Zand, 1997), and various other pieces of work (e.g. Niemeijer and Groot, 2008; Ramos et al., 2007b; Cloquell-Ballester et al., 2006; Spangenberg, 2002; HMSO, 1996; Ott, 1978). In the development of the proposed framework it was assumed that various guidelines and criteria for the selection and development of sustainability indicators could be adapted to suit meta-evaluation needs.

This framework takes into account certain evaluation guidelines that were developed with similar purposes but different 
scopes or targets in mind, in particular the work of Jackson et al. (2000) and Kurtz et al. (2001) on evaluation guidelines for ecological indicators. The research work of Meul et al. (2009), Niemeijer and Groot (2008), Ramos et al. (2008, 2007b), Ramos (2009), Cloquell-Ballester et al. (2006), and Bockstaller and Girardin (2003) was also considered for the key good-practice factors developed.

These key good-practice factors could be viewed as the basis for a checklist, providing aspects that an SDI initiative should be able to cover, though they must be adapted to each particular indicator system. A universal and standardized list of criteria for metaevaluation is not desirable, since it is not realistic to expect a wide consensus on this subject, and also because each specific case requires a customized meta-evaluation tool. Additionally, it will be very difficult to include all the factors desired, so an SDI system could define a prioritizing scheme for key-factor accomplishment, on the basis of the defined objectives and scope of the metaevaluation. This would result in various stages of performance that could be achieved in different periods of time.

It should also be stressed that to conduct or supervise the metaevaluation process a different institution than the one in charge of the SDI system should be involved, thus assuring independent external verification. This can be considered a fundamental step towards guaranteeing the reporting quality, robustness and credibility of the meta-evaluation.

Despite the efforts to obtain a manageable but balanced core set of factors and indicators, the total number is still high. Though a problem, this is mitigated by the fact that different factors and related indicators can be implemented in gradual stages, with a view to accomplishing partial meta-evaluation goals.

Despite many general assumptions, this approach was built to be adopted by a particular SDI set, the SIDS Portugal. This kind of indicator system is a widely used sustainability assessment tool, similar to many other international initiatives. It is characterized by a number of advantages and drawbacks, including the wellknown limitation of domain (economic, social, environmental and social) integration, as discussed by Morse et al. (2001). As stressed in a previous section, SIDS Portugal already plans a metaperformance evaluation step, though it has not yet been developed. Nevertheless, the meta-performance evaluation scheme presented here is perfectly applicable to other SDI systems at the national, regional or local levels, with the necessary adaptations to the needs and constraints of each particular case.

An important practical step in this work will be to apply the framework and associated key good-practice factors and metaperformance indicators developed to real data. For this purpose a user's guide can be produced to explain the methodology in greater detail. This process will allow the usefulness of the approach to be evaluated. Throughout this stage, comparisons with the results of other SDI meta-performance evaluations should be made to help the appraisal process.

\section{Conclusions}

Despite the advantages of SDI systems as tools to assess and report sustainability and the extent to which sustainability indicator frameworks have proliferated, mainly at the country and local levels, most of these frameworks do not include metaevaluation and/or sensitivity analysis procedures or - even less indicators to operate this kind of analysis.

Some work has been carried out to meta-evaluate sustainability indicators and indices, but none of it has tried to meta-evaluate an SDI system as a whole. It is mainly focussed on analysis of the sensitivity of mathematical algorithms that support indices or on more particular thematic tools or domains, such as EIA, or ecological indicators.
In this research, a conceptual framework was developed to design and assess the effectiveness of sustainability indicators. This framework is based on a list of key factors of good practice and on the selection of meta-performance indicators that will allow a more objective and transparent evaluation of overall performancemonitoring activities and results. Public and stakeholder involvement is also an essential component of the proposed framework. It is also argued that a comparison of the results produced by the stakeholders' self-assessment of sustainability and the SDI assessment could be used as an indirect way of complementing the meta-evaluation sustainability results. The comparison between results could be used for crossvalidation of the sustainability meta-evaluation outcomes to allow readjustments, revisions and improvements in SDI systems.

A set of key factors and meta-performance indicators was proposed for adoption in a national case study-the national SDI system, SIDS Portugal. The meta-performance evaluation scheme presented could be applicable to other SDI systems at the national, regional or local levels, if adapted to the needs and constraints of each particular case.

Despite the advantages of these meta-evaluation tools, they also have certain drawbacks. Practical difficulties can arise in their implementation, due to the complexity of sustainability assessment processes. Prioritizing the implementation of the key good-practice factors and related indicators can also be a hard task. Additionally, to assure the feasibility and credibility of the proposed framework, an independent institution (i.e. different from the one in charge of the SDI initiative) should be involved to conduct or supervise the meta-evaluation process.

Additionally, in future developments the use of this metaevaluation framework should be complemented by empirical research approaches, measuring the qualitative dimension of the state of sustainability, trying to minimize time-delay feed-back loops and evaluate the truth value of the SDI system in place.

\section{Acknowledgement}

The authors would like to express their gratitude for the constructive comments provided by the anonymous reviewers.

\section{References}

Ayres, R.U., 2008. Sustainability economics: where do we stand? Ecol. Econ. 67 (2), 281-310.

APA (Agência Portuguesa do Ambiente), 2008. Sistema de indicadores de desenvolvimento sustentável-SIDS Portugal. Agência Portuguesa do Ambiente, Lisboa, $351 \mathrm{pp}$.

Andriantiatsaholiniaina, L.A., Kouikoglou, V.S., Phillis, Y.A., 2004. Evaluating strategies for sustainable development: fuzzy logic reasoning and sensitivity analysis. Ecol. Econ. 48, 149-172.

Becker, J., 2004. Making sustainable development evaluations work. Sustain. Dev. $12,200-211$.

Böhringer, C., Jochem, P.E.P., 2007. Measuring the immeasurable-a survey of sustainability indices. Ecol. Econ. 63, 1-8.

Bockstaller, C., Girardin, P., 2003. How to validate environmental indicators. Agric. Syst. 76, 639-653.

Cloquell-Ballester, V.A., Cloquell-Ballester, V.A., Monterde-Díaz, R., SantamarinaSiurana, M.C., 2006. Indicators validation for the improvement of environmental and social impact quantitative assessment. Environ. Impact Assess. 26, 79105.

DGA (Direcção Geral do Ambiente), 2000. Proposta para um sistema de indicadores de desenvolvimento sustentável. Direcç̃o Geral do Ambiente, Ministério do Ambiente e Ordenamento do Territóri, Lisboa, 223 pp

EC (European Communities), 2004. EU Member State Experiences with Sustainable Development Indicators. Office for Official Publications of the European Communities, Luxembourg: EC.

Funtowicz, S., Ravetz, J., 1993. Science for the post-normal age. Futures 25, 739-755. Funtowicz, S., Ravetz, J., 1994. Emergent complex systems. Futures 26, 568-582.

Gallego, I., 2006. The use of economic, social and environmental indicators as a measure of sustainable development in Spain. Corp. Soc. Responsib. Environ. Mgmt. 13, 78-97. 
Gasparatos, A., El-Haram, M., Horner, M., 2008. A critical review of reductionist approaches for assessing the progress towards sustainability. Environ. Impact Assess. 28, 286-311.

Getzner, M., 1999. Weak and strong sustainability indicators and regional environmental resources. Environ. Manage. Health 10 (3), 170-176.

Hanley, N., Moffatt, I., Faichney, R., Wilson, M., 1999. Measuring sustainability: a time series of alternative indicators for Scotland. Ecol. Econ. 28, 55-73.

Hardi, P., Zand, T., 1997. Assessing Sustainable Development: Principles in Practice. International Institute of Sustainable Development, Winnipeg, Canada, 175 pp.

Her Majesty's Stationery Office (HMSO), 1996. Indicators of Sustainable Development for the United Kingdom. HMSO Publications Centre, Indicators Working Group, Environmental Protection and Statistics and Information Management Division, Department of the Environment, London, $96 \mathrm{pp}$.

Jackson, L.E., Kurtz, J.C., Fisher, W.S. (Eds.), 2000. Evaluation Guidelines for Ecological Indicators. U.S. Environmental Protection Agency, Office of Research and Development, Research Triangle Park, NC (EPA/620/R-99/005).

Lyytimäki, J., Rosenström, U., 2007. Skeletons out of the closet: effectiveness of conceptual framework for communicating sustainable development indicators. Sustain. Dev. 16 (5), 301-313.

Kang, S.M., 2002. A sensitivity analysis of the Korean composite environmental Index. Ecol. Econ. 43, 159-174.

Kurtz, J., Jackson, L.E., Fisher, S., 2001. Strategies for evaluating indicators based on guidelines from the Environmental Protection Agency's Office of Research and Development. Ecol. Indic. 1, 49-60.

Meul, M., Nevens, F., Reheul, D., 2009. Validating sustainability indicators: focus on ecological aspects of Flemish dairy farms. Ecol. Indic. 9 (2), 284-295.

Mitchell, G., 1996. Problems and fundamentals of sustainable development indicators. Sustain. Dev. 4 (1), 1-11.

Morse, S., McNamara, N., Acholo, M., Okwoli, B., 2001. Sustainability indicators: the problem of integration. Sustain. Dev. 9, 1-15.

Ness, B., Urbel-Piirsalu, E., Anderberg, S., Olsson, L., 2007. Categorising tools for sustainability assessment. Ecol. Econ. 60, 498-508.

Niemeijer, D., Groot, R., 2008. A conceptual framework for selecting environmental indicator sets. Ecol. Indic. 8, 14-25.

OECD (Organisation for Economic Co-operation and Development), 1993. OECD Core Set of Indicators for Environmental Performance Reviews. Environment Monographs No. 83, OCDE/GD(93)179. Organization for Economic Co-Operation and Development, Paris.

Ott, W.R., 1978. Environmental Indices-Theory and Practice. Ann Arbor Science, Michigan, $357 \mathrm{pp}$

Parris, T.M., Kate, R.W., 2003. Characterising and measuring sustainable development. Annu. Rev. Environ. Resour. 28, 559-586.

Patel, M., 2002. A meta-evaluation, or quality assessment, of the evaluations in this issue, based on the African Evaluation Guidelines. Eval. Program Plann. $25,329-332$.

Ramos, T.B., Alves, I., Gervásio, I., Liberal, P., 2007a. Revisão do Sistema de Indicadores de Desenvolvimento Sustentável e Apoio na Elaboração, Revisão de Conteúdos e Divulgação do Relatório do Estado do Ambiente. Relatório Final do Projecto desenvolvido no âmbito do Protocolo de Cooperação Técnicocientífica n. $22 / 2005$, estabelecido entre o Instituto do Ambiente e a Universidade do Algarve, Faro.
Ramos, T.B., Alves, I., Subtil, R., Melo, J.J., 2007b. Environmental performance policy indicators for the public sector: the case of the defence sector. J. Environ. Manage. 82, 410-432.

Ramos, T.B., 2009. Development of regional sustainability indicators and the role of academia in this process: the Portuguese practice. J. Clean. Prod., doi:10.1016/ j.jclepro.2009.02.024

Ramos, T.B., Caeiro, S., Douglas, C., Ochieng, C., 2008. Environmental and sustainability impact assessment in small islands: the case of Azores and Madeira. International Journal of Environmental Technology and Management 10 (2), 223-240.

Rapport, D., Friend, A., 1979. Towards a comprehensive framework for environmental statistics: a stress-response approach. Statistics Canada, Catalogue 11510, Ottawa.

RIVM (National Institute of Public Health and the Environment), 1995.In: A Genera Strategy for Integrated Environmental Assessment at the European Environment Agency, Bilthoven, the Netherlands.

RIVM/UNEP (National Institute of Public Health and the Environment/United Nations Environment Programme), 1997. The future of the global environment: a model-based analysis supporting UNEP's First Global Outlook. In: Bakkes, J.A., van Woerden, J.W., Hiraki, A. (Eds.), RIVM 4020017 and UNEP DEIA/TR.97-1. National Institute of Public Health and the Environment and United Nations Environment Programme, Bilthoven, The Netherland.

Rosenström, U., Kyllönen, S., 2007. Impact of a participatory approach to developing national level sustainable development indicators in Finland. J. Environ. Manage. $84,282-298$.

Sadler, B.,2004. On evaluating the success of EIA and SEA. In: Morrison-Saunders, A., Arts, J. (Eds.), Assessing Impact: Handbook of EIA and SEA Follow-up. Earthscan, Portland, p. 338.

Schiller, A., Hunsaker, C.T., Kane, M.A., Wolfe, A.K., Dale, V.H., Suter, G.W., Russell, C.S., Pion, G., Jensen, M.H., Konar, V.C., 2001. Communicating ecological indicators to decision makers and the public. Conserv. Ecol. 5 (1), 19 ([online] URL: http://www.consecol.org/vol5/iss1/art19).

Scipioni, A., Mazzi, A., Zuliani, F., Mason, M., 2008. The ISO 14031 standard to guide the urban sustainability measurement process: an Italian experience. J. Clean. Prod. 16, 1247-1257.

Scriven, M., 1969. An Introduction to Meta-evaluation. Educ. Prod. Rep. 2 (5), 36-38.

Singh, R.K., Murty, H.R., Gupta, S.K., Dikshit, A.K., 2007. Development of composite sustainability performance index for steel industry. Ecol. Indic. 7, 565-588.

Singh, R.K., Murty, H.R., Gupta, S.K., Dikshit, A.K., 2009. An overview of sustainability assessment methodologies. Ecol. Indic. 9, 189-212.

Spangenberg, J., 2002. Institutional sustainability indicators: an analysis of the institutions in Agenda 21 and a draft set of indicators for monitoring their effectivity. Sustain. Dev. 10, 103-115.

UN (United Nations), 1996. Indicators of Sustainable Development: Framework and Methodologies. United Nations Department for Policy Co-ordination and Sustainable Development, New York.

Walz, R., 2000. Development of environmental systems: experiences from Germany. Environ. Manage. 25 (6), 613-623.

Wilson, J., Tyedmers, P., Pelot, R., 2007. Contrasting and comparing sustainable development indicator metrics. Ecol. Indic. 7, 299-314. 